\title{
Preservation Efforts in Larger U.S. Academic Libraries
}

\begin{abstract}
A survey of preservation activities in large U.S. academic libraries revealed widespread problems of deterioration of library materials. The majority of respondents have developed some countermeasures, and various procedures are examined. Recommendations are made for establishing a preservation unit. It is evident that further communication in this area is seriously needed.
\end{abstract}

$\mathrm{T}$

HE PHYSICAL DETERIORATION OF LIBRARY MATERIALS is a critical problem facing academic libraries everywhere. Acid impurities introduced during paper production since the mid-nineteenth century and assimilated since from air pollutants cause a breakdown of the cellulose molecule and ultimate total deterioration of the paper. Harmful environmental conditions, such as heat and humidity extremes, aid in this destruction. ${ }^{1}$ The deterioration problem is often assigned a low priority due to insufficient funds or personnel and the lack of large-scale technical solutions. The importance and support accorded preservation efforts must increase if library collections so carefully developed over the last hundred years are to last beyond the coming generation of users.

Book conservators and researchers are developing long-term preservation measures such as deacidification for important materials. ${ }^{2}$ Two of the largest nonacademic libraries, the New York Public Library and the Library of Congress,

Gay Walker is preservation librarian, Yale University Library, New Haven, Connecticut. have established comprehensive conservation sections, the latter with its own research laboratory. Unfortunately, there are so far few academic libraries able or rich enough to institute these techniques to preserve large numbers of volumes in poor condition. Realistic alternatives to restoration have been implemented at various libraries, including reproduction, replacement, and withdrawal of deteriorated materials. This article presents the results of a survey, conducted in 1972, which confirms the existence of preservation efforts, their magnitude, and procedures. The questions asked were developed from experience in the Preservation Project at the Yale University Library.

Questionnaires were sent to 115 academic libraries, all with holdings of 500,000 volumes or more. Eighty-six libraries, about 75 percent, replied, and many expressed a deep concern over preservation problems.

\section{EFFORTS UNDERTAKEN}

Sixty-two libraries, or 72 percent, reported some preservation procedures. Although many are small "repair or reshelve" operations, a few have devel- 
oped more sophisticated programs of replacement, reproduction, withdrawal, and special repairs.

Though deterioration was not a problem for a few recently opened or smaller libraries, several larger libraries indicated severe budgetary limitations which prevented any preservation action. At least four libraries have independent preservation operations with one or more persons engaged primarily in preservation activities of an organizational and decision-making nature. Thirty-nine libraries reported preservation activities associated with technical services, and fifteen reported preservation activities associated with circulation.

All programs handle high-use items in disrepair; forty libraries use stack checks to discover other items needing preservation attention; twenty libraries use inventory; and twenty-five rely upon staff reports. Most titles processed are recently circulated items. Two libraries expressed plans to check systematically through their entire collection for deteriorated materials. It should be noted that twenty-one libraries have never taken a full inventory; and the majority give lower priority to items in storage collections.

Patron or staff recommendations on deteriorated items are generally acted upon. Consultation with subject specialists concerning such materials is generally done only in special cases.

Most libraries check the condition of other copies or editions of a deteriorated item before deciding on its disposal. The reprint remains the most attractive form of replacement for both the deteriorated monograph and serial and is twice as popular as out-of-print searching in the case of monographs. The main drawback cited for reprints is high cost, although bibliographic accuracy presents problems.

One librarian commented, "Replacing a book with another from the same printing is in general senseless in that the life expectancy of the second is also low." Microfilm and microfiche were acceptable to fewer libraries.

Almost all participating libraries attempt to replace out-of-print deteriorated volumes. While a few discard the originals outright and some leave them on the open shelves, the majority of libraries keep the originals in storage areas or "brittle book collections" until the replacement arrives. One library's solution for deteriorated volumes difficult to replace is to put the book in a pamphlet binder "so that it is available as long as possible." Approximately onethird of these libraries resell some of the withdrawn volumes.

At least two libraries have a separate preservation budget for replacements and reproductions, and seven use inhouse reproduction facilities to produce replacements.

The large majority of the libraries surveyed attempt to replace serials which are beyond repair, and most own partial serial runs on film. It is more popular to use film for serial than for monographic replacement although reprints are still the first choice.

Attempts are generally made to identify fragments while books with missing pages are either replaced or completed by photocopying. No libraries are using technological preservation methods on a large scale in their main collections, and only one indicated immediate plans for such a step. That library planned the use of the vapor phase deacidification process.

The numbers of deteriorated volumes processed illustrate the casual approach to preservation taken by most large academic libraries. Thirty-two libraries handled less than 300 such volumes per year. Only one library estimated that the deteriorated items processed annually came to more than 1 percent of the collection. Four libraries, however, maintained records and processed more than 1,000 volumes yearly in an aggressive 
and systematic attack on the deterioration problem.

\section{A Model Preservation Program}

Although every library is dealing with a slightly different situation in terms of book deterioration, many aspects of establishing a preservation program can be generalized. What follows is an outline of some of the goals, considerations, and processes thought important by this author in setting up a preservation program.

Initial planning for a preservation program should insure a thorough, coherent approach to the many aspects of preservation which affect all sections of the library and may include binding, repair, reprography, and collection management along with the actual preservation section. It is ideal to have one person in charge of the operation who will concentrate on overall organization and special projects, keep criteria consistent, establish priorities, and guide decision making. This person should have the necessary authority to establish procedures and implement decisions and should be responsible for keeping informed on new developments, educating staff and patrons, planning for emergencies, and recommending preventive environmental conditions and procedures for the entire library system. Many departments will be affected, and both budgetary and organizational changes should be anticipated. Independence for the preservation program is recommended, but it may be necessary to start in association with another department. The circulation department can identify deteriorated items after circulation and will know high-use areas and collection idiosyncrasies. Other departments, such as cataloging or binding, may provide equally helpful connections for preservation efforts.

One of the first steps should be a survey of stack conditions to determine the scope of the problem. This will aid in planning the actual program, its housing and personnel, and the involvement of other departments. It will also aid in providing hard facts for budgetary consideration. Another early step should be the formulation of a preservation policy which establishes criteria and goals.

Deteriorated items are most easily identified after use by circulation personnel. Focusing on these high-demand items is an obvious priority, although many research items receive little use but may be of critical importance. An inventory, while clearing up missingbook problems, can also be used for identifying deteriorated volumes.

Each deteriorated item should be reviewed with certain information available: its relation to the collection and its commercial availability in reprint or microform. After making a record for the item to allow bibliographic control and user access, a search form should be made which will ultimately contain all necessary information about that item. Relevant volumes (other editions, duplicates, rest of the set) should be examined for condition where possible. For instance, if an exact duplicate in good condition is held, the deteriorated copy might be withdrawn unless the use pattern suggests duplication. Items with poor paper which cannot be repaired should be searched in the trade bibliographies to determine availability. ${ }^{3}$ With this information, an acceptable decision on the disposal of research materials can be made by the appropriate bibliographer, curator, or subject specialist. If criteria for peripheral materials (such as mysteries, certain subject areas) are clear enough, a decision may be made without this additional information.

The decision-making process, though unique for each library, must be cooperative. The head of the preservation unit should act as a check, obtaining second opinions where necessary and maintaining a consistent approach to all materials. The disposal options should be 
made clear to the specialist consulted, and comparative costs of alternatives should be available. Each volume must be reviewed, the bulk usually by the bibliographers or book selectors or a staff specialist. Curators of special collections and branch librarians are also important consultants. The request for recommendations on particular titles from faculty specialists encourages interest and can provide valuable expertise as well. Weeding routines may provide useful aids, especially in terms of consulting procedures.

\section{Monographs}

Decisions must be made for each monographic title based on its value and relation to the collection. Postponing action on identified volumes in poor condition or even tying or boxing items to last "as long as possible" is a disservice to the research collection. Titles already part of the collection may be as important as new additions, and it is fair to make decisions on a competitive basis with new acquisitions. However, it appears preferable to set aside funds specifically for preservation replacement, reproduction, and repair so that the value and position of each book may be given the fullest consideration. A separate "brittle book" collection does not solve the problem of deteriorated items and may result in total loss. Storage collections may become "poor paper depositories," so criteria for storage should be carefully examined.

The alternatives available for decision making may vary with each library as many options are dependent upon additional funds or special personnel. The major options are to repair, rebind, replace, reproduce, withdraw, or reshelve. The need for complete freedom in the choice of alternatives is evident. The repair or rebinding of an item depends on the condition of the paper, cost, and familiarity with the binders who serve the library. It may be more feasible to replace a research item with a reprint than undertake expensive repair work. Criteria for rare and semirare books will, of course, be different, and consultation with the appropriate specialist is necessary. The workload from these two categories must be reviewed with the binding unit to set up a tenable routine.

Facsimile reprints are generally the most satisfactory replacement format. The advantages of reprints are many: paper used for reprinting is often longer-lasting (such as the permanent/durable paper developed by the Barrow Laboratory which should last at least 300 years $) ;{ }^{4}$ the format is identical to that of the original; printing is on both sides of the page; and the book is bound and easy to use in the conventional format. The retention of deteriorated materials until they are physically replaced is critical to the continued availability of the text. Direct control should be maintained over deteriorated items awaiting replacement; a special area is best, with controlled user access, no circulation, and supervision of the physical and record withdrawal. Experience has shown that out-of-print searching for exact replacements of deteriorated materials should be avoided due to similarity in paper conditions and the unjustified expense in obtaining, at best, a very temporary solution.

If deteriorated items are needed and not available commercially, hard copy reproduction (with due respect for copyright restrictions )-either by photoduplication, using permanent/durable paper, or by the more expensive enlarged paper copy method from a negative microfilm-is necessary. Microfilming is usually the second choice, depending on the nature of the item, how large it is, and its use in the collection.

It is helpful to have a written policy outlining general criteria for withdrawal (such as off-prints, out-of-scope, lowuse duplicates, mysteries, or areas of branch library responsibilities), but in- 
dividual judgments should be made in each case. Books withdrawn or replaced should have call numbers and plates marked out and date slips removed immediately. Otherwise, books are likely to turn up on the shelves again. Resale of suitable items via library sales or dealers can be economically beneficial to the library.

Personnel involved in preservation must be careful to avoid being overzealous. Does the item really require attention, or can it be reshelved or labeled only? Experience will be the best guide to choosing items needing immediate attention.

\section{Serials}

Deteriorated serial volumes present other difficulties as the condition of the whole run may be poor. When repairs are not sufficient or feasible, the preservation decision must be made on the basis of use, availability of replacement, and value. The ideal disposal decision will take into account the condition of the entire run, to avoid later duplication of effort. The more popular serial titles are sometimes in print, but titles of highly specialized research value must be carefully preserved or reproduced (with due regard to copyright restrictions). Cooperative reproduction or transfers are attractive possibilities. Serials can be accumulated and the complete run of each title checked as to physical condition. In this way, cost estimates can be made for the alternatives on every title. Replacements would be chosen according to value and the state of the run; if the whole run is poor, it might be placed on microfilm while one or a few poor volumes might be replaced by hard copies. The replacement for any item read as a single unit and receiving at least moderate use may be preferable as a hard copy.

It is best to attempt identification of fragments immediately upon receipt as they are an indication of worn or de- teriorated material which should be processed as soon as possible to prevent further loss. Interlibrary loans may be used to copy missing pages, and it is best to use permanent/durable paper for all such photocopying.

\section{Other Considerations}

A general "awareness campaign" for both staff and patrons will greatly benefit preservation efforts and encourage involvement. Educational activities such as tours, exhibits, hand-outs, bibliographies, or "Conservation Days" will serve as good advertising and may bring valuable help from faculty and other specialists. Preservation activities are critical to the research collection and provide service of immediate benefit to both patrons and staff, and a clear understanding of the program is important.

Few libraries have fully documented their preservation efforts. ${ }^{5}$ The maintenance of careful statistical records is essential for preservation activities and should be a basic requirement. Each library has apparently developed its own standards and criteria for decision making for deteriorated items, and though one policy would be impractical for all libraries, with their differences in budget, manpower, and philosophy, perhaps helpful guidelines may be drawn up to help the organization of preservation programs at other libraries in the future.

\section{Conclusion}

The deterioration of library materials is of critical proportions for large American academic libraries. As this problem becomes more apparent to library administrators, more separate preservation programs will be established. Some suggestions have been made for the establishment of a preservation unit on a small scale. The survey reported here shows that many independent approaches have been made in handling deteriorated library materials 
but that only three or four academic libraries have instigated preservation programs to deal with the problem in its entirety. These libraries should communicate their findings and methods of oper- ation so others may benefit from past experiences. Such cooperation is essential for a successful, on-going campaign to preserve library collections.

\section{REFERENCES}

1. The two-volume title by George Cunha and Dorothy Cunha, Conservation of Library Materials (2d ed.; Metuchen, N.J.: Scarecrow, 1971), gives an excellent overview and bibliography for the entire field of preservation including storage conditions. A comprehensive scientific essay on storage conditions can be found in Carl Wessel, "Environmental Factors Affecting the Permanence of Library Materials," in Howard W. Winger, ed., Deterioration and Preservation of Library Materials (Chicago: Univ. of Chicago Pr., 1970), p.39-84. A good discussion of the subject in layman's terms is presented by Paul Banks, "Environmental Standards for Storage of Books and Manuscripts," Library Journal 99:339-43 (Feb. $1,1974)$.

2. In particular, see papers by Richard Daniel Smith on paper preservation and deacidification, especially his "Paper Impermanence as a Consequence of $\mathrm{pH}$ and Storage Conditions," Library Quarterly 39:153-95 (April 1969).

3. See Alfred Lane, "Reprints in the Preserva- tion Picture; And a Drift Aside," Special Libraries 63:305-9 (July 1972).

4. See the works by William J. Barrow and his laboratory, especially the series entitled $\mathrm{Per}$ manence/Durability of the Book (Richmond, Va.: W. J. Barrow Research Laboratory, 1963-1969), I-VI. A good overview of the paper problem and its history can be found in Verner Clapp, "The Story of Permanent Durable Book Papers, 1115-1970," Restaurator (Supplement 2; 1972), p.1-51.

5. The following are relevant works on local preservation programs: Hannah B. Friedman, "Preservation Programs in New York State: Existent and Non-existent," Special Libraries 60:578-89 (Nov. 1969); Hannah B. Friedman, "Preservation of Library Materials: The State of the Art," Special Libraries 59:608-13 (Oct. 1968); James W. Henderson and Robert G. Krupp, "The Librarian as Conservator," Library Quarterly 40:17692 (Jan. 1970); and Frazer G. Poole, "Preservation Costs and Standards," Special Libraries 59:614-19 (Oct. 1968). 